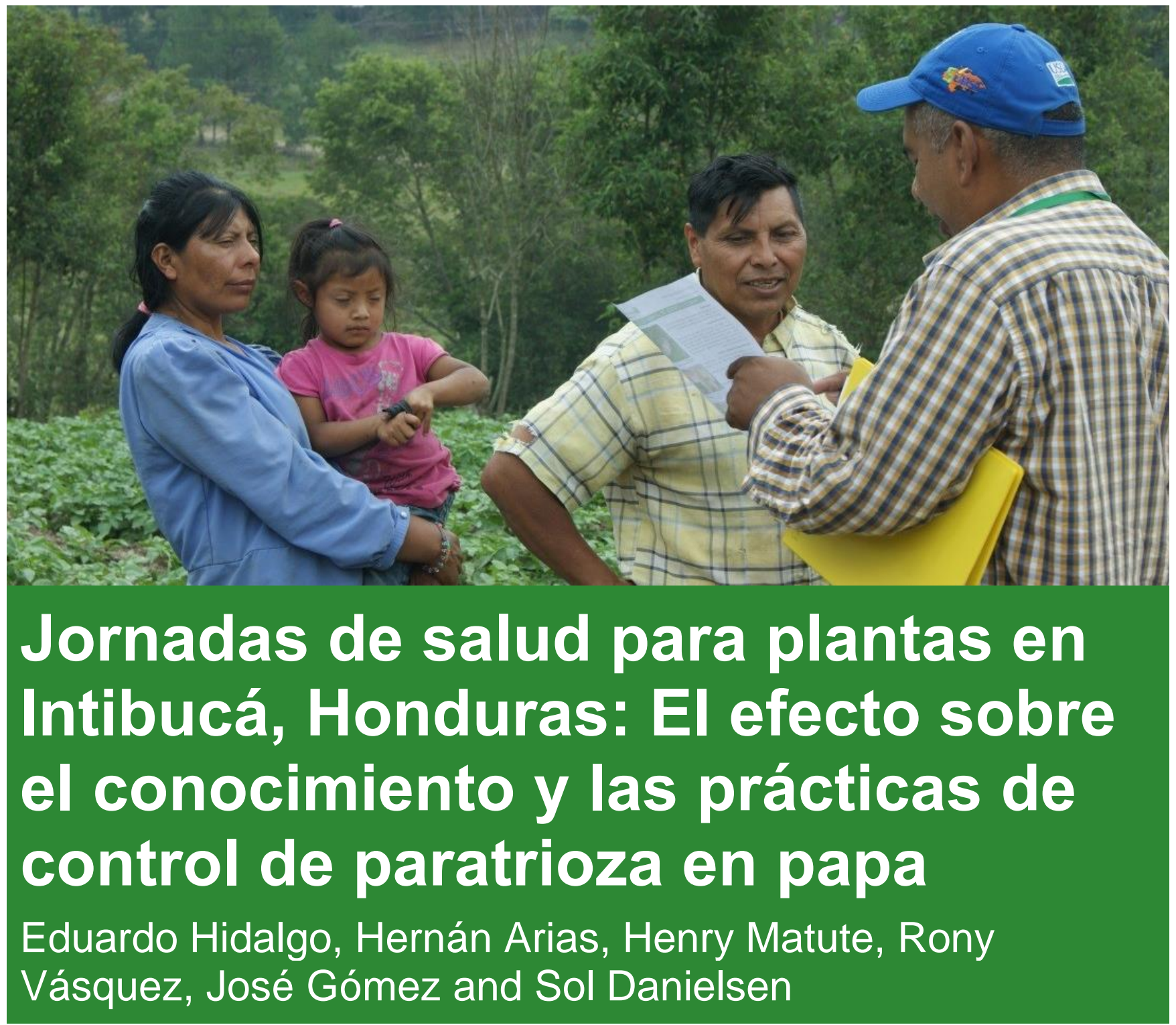

\title{
Summary
}

Desde su introducción en Honduras en el 2002, la paratrioza, una plaga devastadora de la papa, ha ido ganando fuerza sobre todo en el departamento de Intibucá, la zona papera más importante del país. Empezando en el 2014, el Servicio Nacional de Sanidad e Inocuidad Agroalimentaria (SENASA), en colaboración con el programa Plantwise de CABI, ha implementado varias jornadas de salud para plantas en Intibucá para diseminar información sobre el manejo de la paratrioza entre los agricultores de papa. En abril del 2017 se llevó a cabo un pequeño estudio de caso para averiguar el efecto de estas jornadas sobre el conocimiento y las prácticas utilizadas por los agricultores.

\section{Hallazgos principales}

- Los agricultores que han participado en jornadas de salud de plantas han mejorado su nivel de conocimiento sobre la plaga y las prácticas de control.

- Pese a que en las jornadas se promueve el monitoreo como base para la toma de decisión, ya que ayuda a definir la necesidad de aplicar medidas de control, la mayoría de los agricultores prefieren hacer aplicaciones calendarizadas. Aunque la mayoría han escuchado de trampas amarillas, nadie las usa.

- Los agricultores que participaron en las jornadas tienden a usar insecticidas menos tóxicos (clase III y IV) que los no participantes. 
- Los agricultores de la región reciben visitas de múltiples organizaciones proveedoras de asistencia técnica. Los mensajes no armonizados sobre los mismos temas a veces confunden a la gente.

- La distancia entre los pueblos y la baja densidad poblacional hace difícil alcanzar grandes números de agricultores con el mensaje de las jornadas e igualmente dificulta las actividades de seguimiento para verificar el impacto de las mismas.

- Es necesario buscar el acercamiento y coordinación entre oferentes de asesoría técnica que visitan la región para armonizar los mensajes de extensión y optimizar el alcance a la comunidad de agricultores con los recursos disponibles.

\section{El caso}

\section{La paratrioza en Honduras}

Intibucá es la zona productora de papa más importante de Honduras cubriendo cerca de $80 \%$ del área de producción nacional (Toledo, 2013). La mayoría de los lencas, una de las etnias más importantes del país, reside en Intibucá. Según la municipalidad alrededor de 4,500 familias lencas dependen mayormente de la producción de papas.

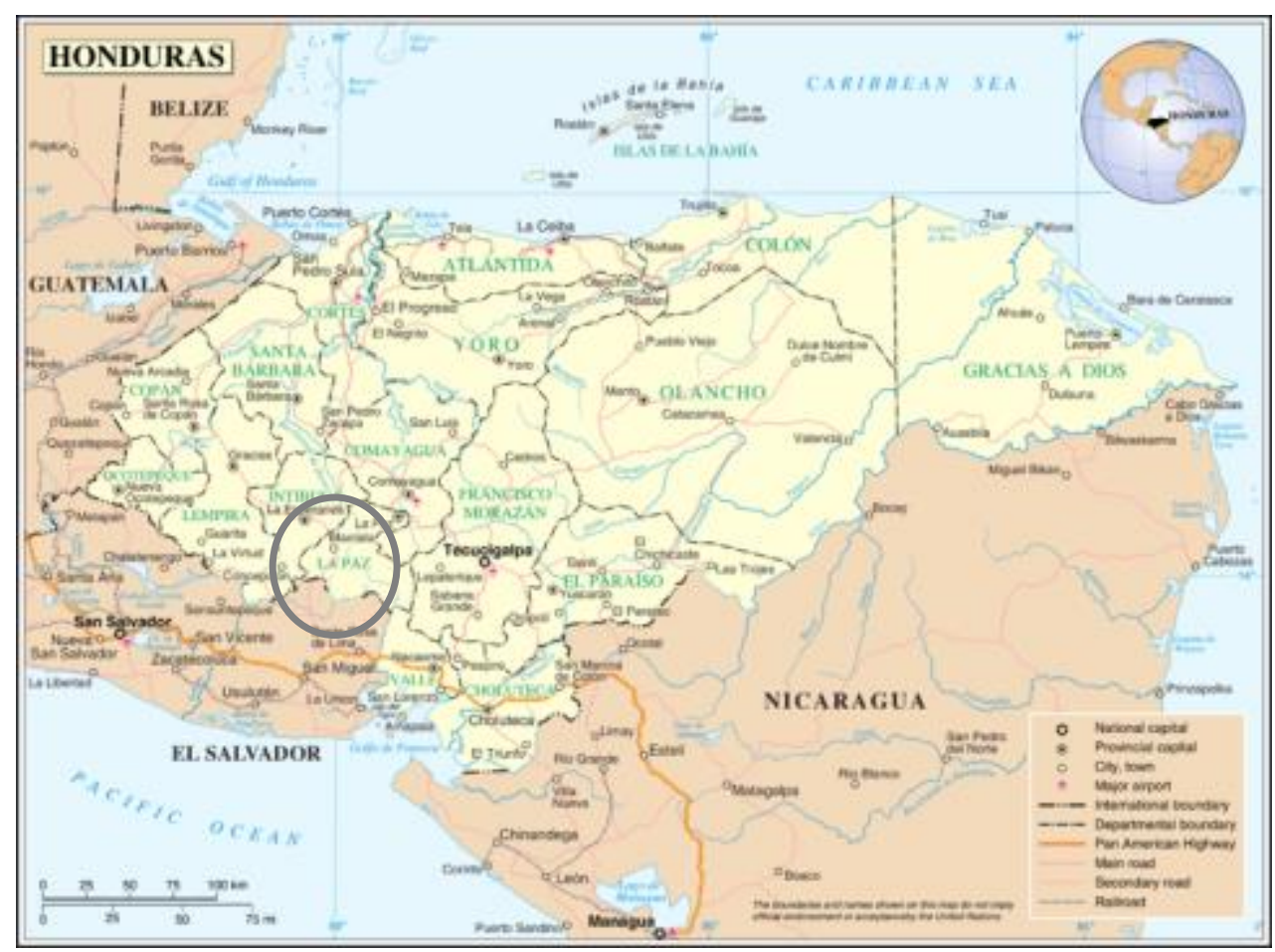

Mapa de Honduras. El círculo marca el Departamento de Intibucá.

La paratrioza (o psílido) de la papa fue reportada en Honduras por primera vez en 2002 y su presencia confirmada en 2009 por Rehman et al. (2010). Entre 2006 y 2010 se reportaron varios ataques severos en Ocotepeque e Intibucá causando pérdidas considerables (Espinoza, 2010; Espinoza et al., 2014). El insecto se ha diseminado rápidamente por Centro América desde el 2010 (Bujanos y Ramos, 2015) causando grandes pérdidas económicas y poniendo en peligro el estatus papero de Intibucá. 
En un esfuerzo para controlar la plaga las autoridades sanitarias en el 2011 intentó decretar una veda a la papa en la región del occidente ${ }^{1}$ pero esto no fue posible pues la papa es la principal fuente de ingresos de la región. En su lugar, durante los años 2011 y 2012, SENASA organizó comités regionales de sanidad vegetal y un comité técnico de asistencia con un programa de capacitación para productores, se creó el comité de la papa, y se reguló la venta indiscriminada de productos ineficientes para el control de la plaga, además de las importaciones ilegales de semilla, logrando así bajar las poblaciones del insecto vector de la enfermedad. Pese a estos esfuerzos en 2014 la plaga vuelve a aparecer como una amenaza importante provocando comentarios en los periódicos tales como: la paratrioza "tiene asustados, o mejor dicho, "casi de rodillas", a muchos productores y técnicos de papa" 2

Es posible que los cambios climáticos sean parte de las causas del aumento en la incidencia de la paratrioza. El Organismo Internacional Regional de Sanidad Agropecuaria (OIRSA) considera Intibucá dentro de las zonas de alto riesgo de experimentar anomalías climáticas (OIRSA, 2016).

La paratrioza es una plaga complicada, que también afecta al tomate y otras Solanáceas, con varios efectos dañinos. Además de causar daño por sí solo, al alimentarse las ninfas de la planta, el insecto es portador de una bacteria que introduce a las plantas cuando se alimenta de ella (DICTA, 2016). Las enfermedades causadas tienen varios nombres: Amarillamiento del psílido y papa macho (causado por el insecto) y papa manchada, papa rayada, punta morada, zebra chip y papa dulce (causado por la bacteria). El daño que la bacteria causa hace que la papa no sea apta para consumo o procesamiento industrial ya que reduce su calidad.

\section{Jornadas de salud de plantas}

Desde el 2014, el Servicio Nacional de Sanidad e Inocuidad Agroalimentaria de Honduras (SENASA) en colaboración con el programa Plantwise, coordinado a nivel global por CABI, ha usado las jornadas de salud de plantas como un método para diseminar mensajes de extensión sobre problemas de gran importancia en las áreas de incidencia. La jornada consiste en la diseminación de mini hoja volantes acompañadas por una charla corta sobre uno o dos problemáticas locales.

Antes de iniciar las jornadas, en setiembre de 2014, el equipo del programa llevó a cabo un taller para enseñar a los doctores de plantas cómo elaborar el material para la jornada (hojas volantes, foto páginas) y cómo transmitir efectivamente un mensaje a los agricultores y agricultoras durante el evento. En ese mismo taller los doctores de plantas identificaron a la paratrioza como uno de los dos problemas de importancia en la región por su alta incidencia, siendo el otro el tizón tardío de la papa. La mini hoja volante elaborada en el taller contiene una lista de 12 opciones de manejo de la paratrioza (ver abajo). Esta hoja define el contenido de las jornadas. En la búsqueda del mejor modelo SENASA ha usado varias modalidades de jornadas de salud, operando desde mercados y escuelas, como parte de eventos comunales o haciendo recorridos por parcelas de agricultores y agricultoras.

\footnotetext{
1 http://www.laprensa.hn/economia/542210-97/decretan-veda-a-cultivos-de-papa-en-honduras

2 http://www.elheraldo.hn/alfrente/566239-209/honduras-seis-plagas-amenazan-rubros-clave
} 


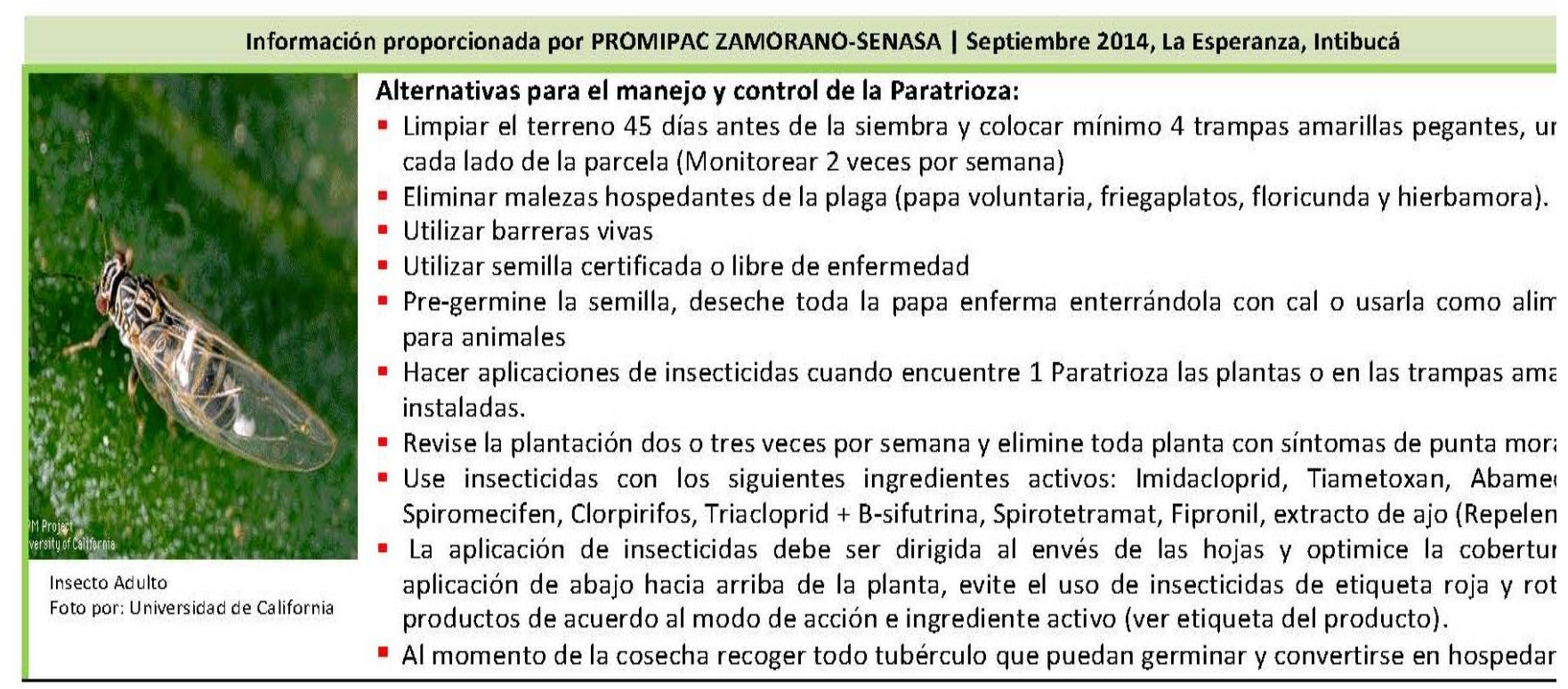

Mini hoja volante sobre la paratrioza entregada a los participantes de las jornadas de salud en Intibucá

Desde setiembre de 2014 a noviembre de 2016 se llevaron a cabo un total de 24 jornadas en Intibucá, Comayagua y Ocotepeque con la participación de 722 personas (aprox. 65\% hombres y $35 \%$ mujeres) (ver Cuadro 1). La gran mayoría de los participantes entrevistados (90\%) dijeron que tenían el problema de paratrioza en su parcela. Además, en 2016 SENASA repartió 1,230 mini hojas volantes ${ }^{3}$ a través de agropecuarias, escuelas y municipalidades.

\section{Cuadro 1. Jornadas de salud de plantas sobre la paratrioza realizadas por Plantwise y SENASA.}

\begin{tabular}{|l|l|c|c|c|}
\hline \multirow{2}{*}{ Fecha } & \multirow{2}{*}{ Lugares } & \multicolumn{3}{|c|}{ Número de } \\
\cline { 3 - 5 } Sarticipantes \\
\hline Set 2014 & $\begin{array}{l}\text { La Esperanza, Chiligatoro, Azacualpa, El Rodeo, Malguara - } \\
\text { Intibucá }\end{array}$ & n.d. & n.d. & 110 \\
\hline Oct 2014 & Ocotepeque - Comayagua & n.d. & n.d. & 328 \\
\hline Mar 2015 & La Esperanza - Intibucá & n.d. & n.d. & 65 \\
\hline Abr 2015 & Laguna Seca de Mercedes - Octotepeque & n.d. & n.d. & 16 \\
\hline Set 2015 & La Esperanza - Intibucá & n.d. & n.d. & 23 \\
\hline Dic 2015 & San Juan - Intibucá & n.d. & n.d. & 17 \\
\hline Feb 2016 & Chiligatoro, Moquecagua, Yamaranguila - Intibucá & 31 & 17 & 48 \\
\hline Mayo 2016 & Rio Grande - Intibucá & 14 & 18 & 32 \\
\hline Jun 2016 & El Rodeo - Intibucá & 10 & 10 & 20 \\
\hline Oct 2016 & Pueblo Viejo, Cruz Alta, Chiligatoro, Yamaranguila - Intibucá & 15 & 7 & 22 \\
\hline Nov 2016 & Las Hortencias, Malguara, El Tambor - Intibucá & 35 & 6 & 41 \\
\hline Total & & $\mathbf{1 0 5}$ & $\mathbf{5 8}$ & $\mathbf{7 2 2}$ \\
\hline
\end{tabular}

$\mathrm{H}$ - hombres; $\mathrm{M}$ - mujeres

n.d. - no documentado

\footnotetext{
${ }^{3}$ No hay un registro de los agricultores que recibieron la información.
}

Jornadas de salud para plantas en Intibucá, Honduras: El efecto sobre el conocimiento y las prácticas de control de paratrioza en papa 
En Abril del 2017, un equipo de CABI y SENASA llevó a cabo un pequeño estudio para evaluar el efecto de las jornadas sobre el conocimiento, las percepciones y prácticas de los agricultores acerca de la paratrioza de la papa. En otras palabras, ¿qué pasa después que los agricultores reciben el mensaje de extensión?

\section{Métodos}

Una pequeña encuesta fue llevada a cabo entre el 25 y 26 de abril de 2017 en cinco comunidades de Intibucá: Río Grande, Azacualpa, Malguara, El Rodeo y Chiligatoro. Un total de 22 agricultores (11 participantes y 11 no-participantes de jornadas) fueron entrevistados, 13 hombres y 9 mujeres.

Los agricultores y las agricultoras que participaron en la jornada, y que fueron tomados en consideración en la encuesta, fueron seleccionados arbitrariamente de la lista de participantes de dichas jornadas, mientras que los agricultores que no participaron en la jornada fueron seleccionados al azar al momento de llegar al sitio.

El cuestionario usado fue diseñado alrededor de los materiales de apoyo mostrados en la siguiente página. Las dos fotopáginas (A, B) sirvieron para captar el conocimiento del agricultor sobre malezas hospedantes del insecto y los diferentes síntomas de la enfermedad que cause. La hoja volante (C) sirvió para saber si el agricultor había visto o recibido el material, si conocía cada una de las doce recomendaciones dadas, si las había aplicado y qué opinaba de las prácticas.

La comparación entre participantes y no-participantes fue hecha a través de presentación gráfica y estadística descriptiva.
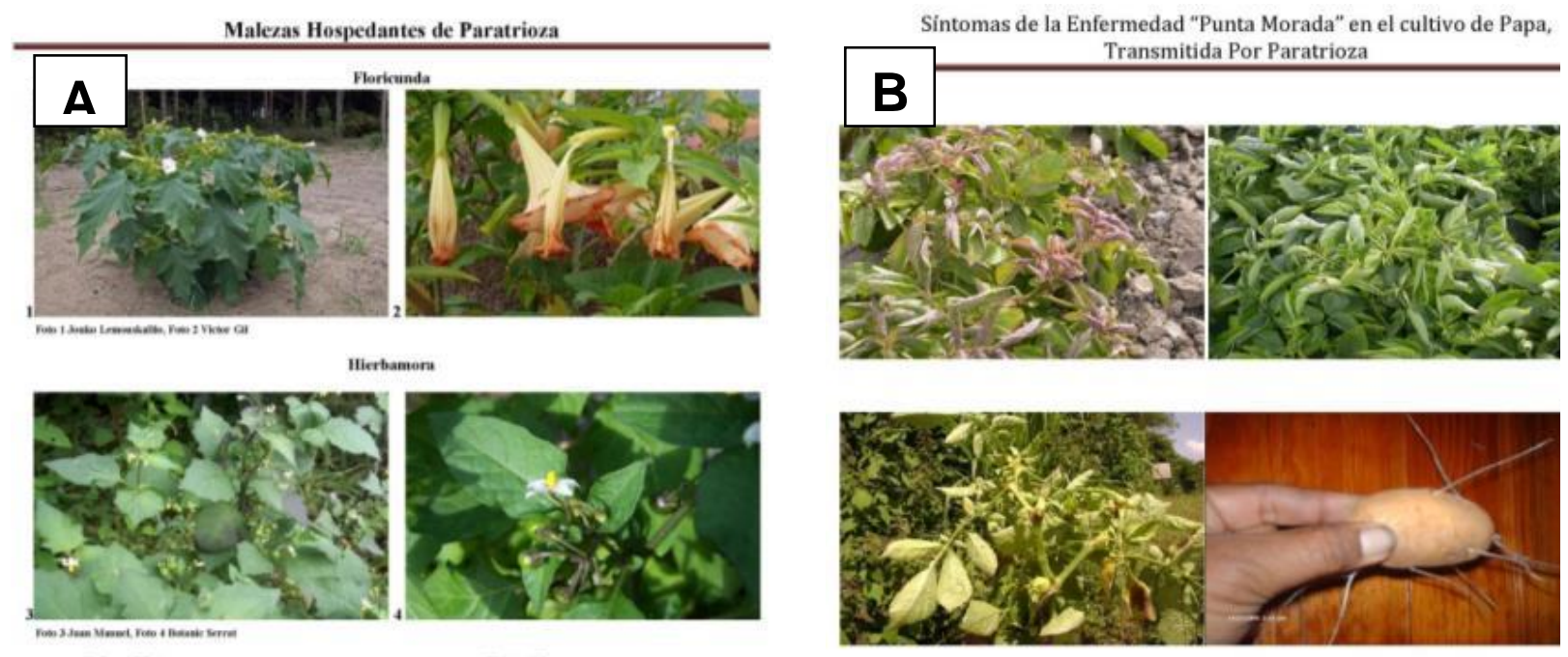

Friega Plation

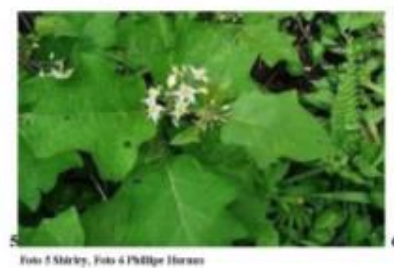

Tamatillo

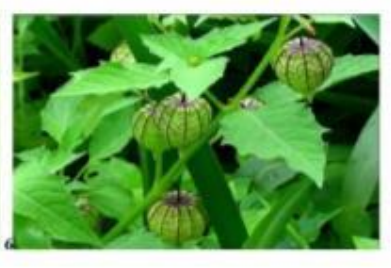

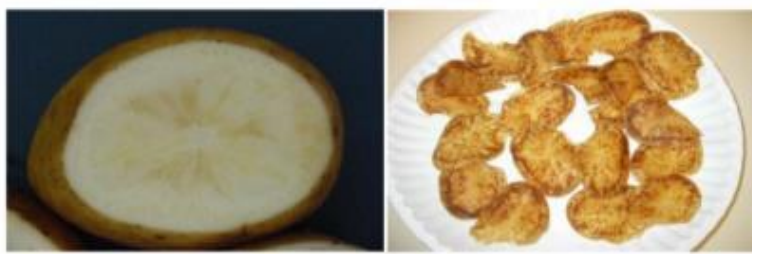




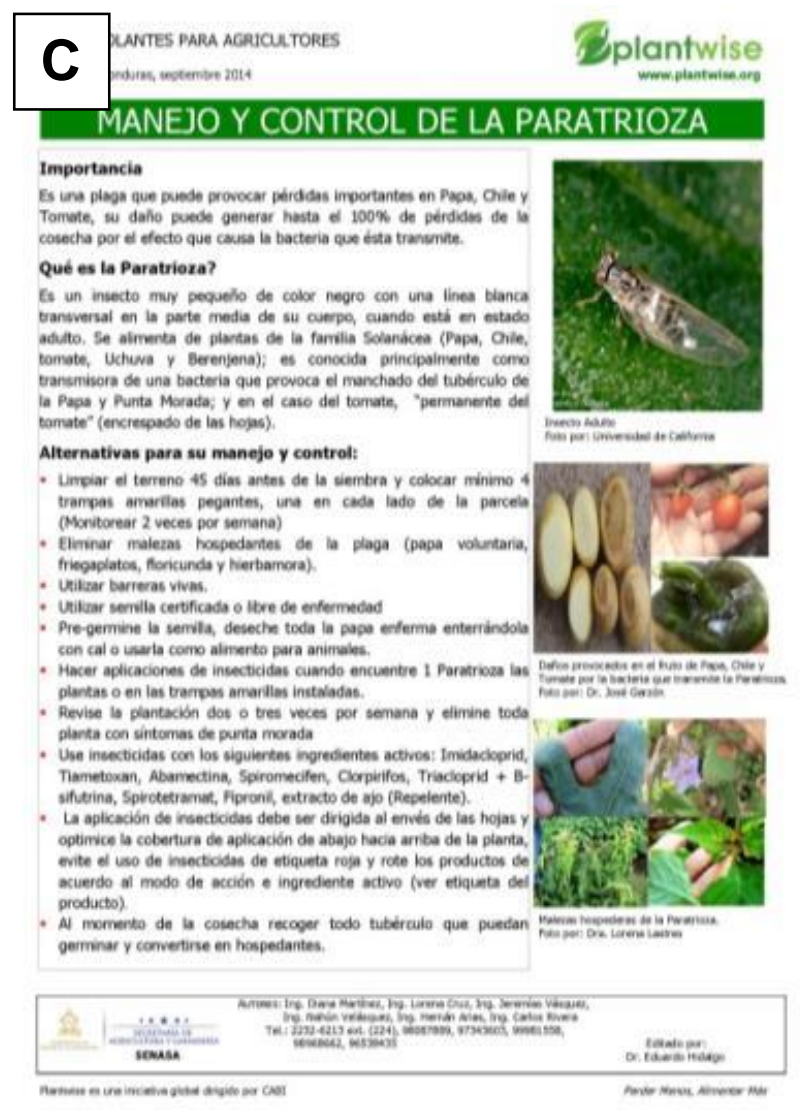

Materiales de apoyo usados durante las entrevistas con agricultores y agricultoras:
A. Fotopágina con malezas hospedantes (friegaplato, hierbamora, floricunda, tomatillo).
B. Fotopágina con síntomas de paratrioza (y punta morada, zebra chip).
C. Hoja volante con medidas de control de paratrioza.

\section{Resultados y discusión}

\section{Conocimiento de la plaga}

Los agricultores usan múltiples nombres para caracterizar a la enfermedad, tanto nombres técnicos como nombres locales (Figura 1). Paratrioza fue el nombre más común seguido por papa/ semilla macho, mosca, papa dulce entre otros. Punta/hoja morada o punta roja fue mencionado pocas veces.

La diversidad de nombres refleja la gran complejidad de la enfermedad que se manifiesta con diferentes síntomas en las distintas etapas de desarrollo de la planta. Algunos nombres se refieren al efecto del insecto, otros al efecto de la bacteria.

El nombre papa dulce describe bien uno de los efectos principales de la plaga: los cambios químicos inducidos por la bacteria hacen dulce el tubérculo. Cuatro personas mencionaron que el tubérculo se pone dulce y ya no se puede vender. Una señora que se encontraba en una plaza frente a un centro de acopio de papa en Malguara dijo, "Dicen que vendemos caña [de azúcar], ya no es papa", refiriéndose a los comercializadores que rechazan la papa.

La presencia de una mosca fue la seña más observada. Una señora de Río Grande dijo "Hay una mosca que jode la papa." José Adán y Santos Neemías Sánchez, jóvenes agricultores de Pueblo Viejo, pero que tienen su parcela en Malguara, mencionaron que el insecto está al envés de la hoja. Además estimaron que la pérdida puede ser hasta $50 \%$, donde la papa se vuelve dulce y no se puede vender.

En cambio, nadie sabía que la enfermedad es causada por una bacteria transmitida por la paratrioza. No obstante, varios agricultores si sabían

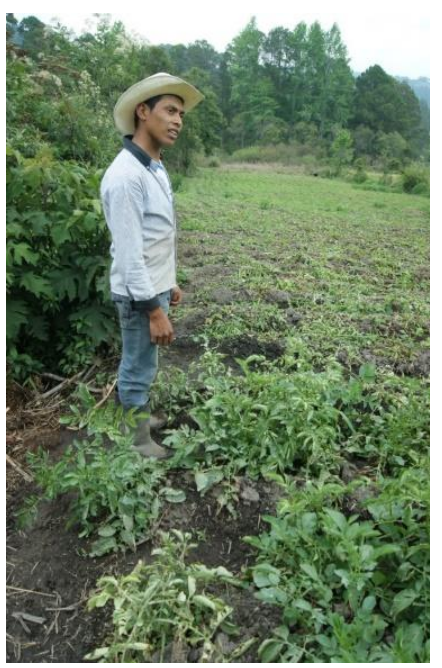

Santos Neemías Sánchez, joven agricultor en Malguara, explica que la paratrioza aumenta cuando hace mucho calor

Jornadas de salud para plantas en Intibucá, Honduras: El efecto sobre el conocimiento y las prácticas de control de paratrioza en papa 
que la mosca trae 'algo'. Uno dijo, "la mosca se mete por debajo y le mete el problema", y otra que "las plantas están enfermas por la mosca". Varios de los respondientes han observado que hay más problema de paratrioza en zonas cálidas, que le "gusta el verano".

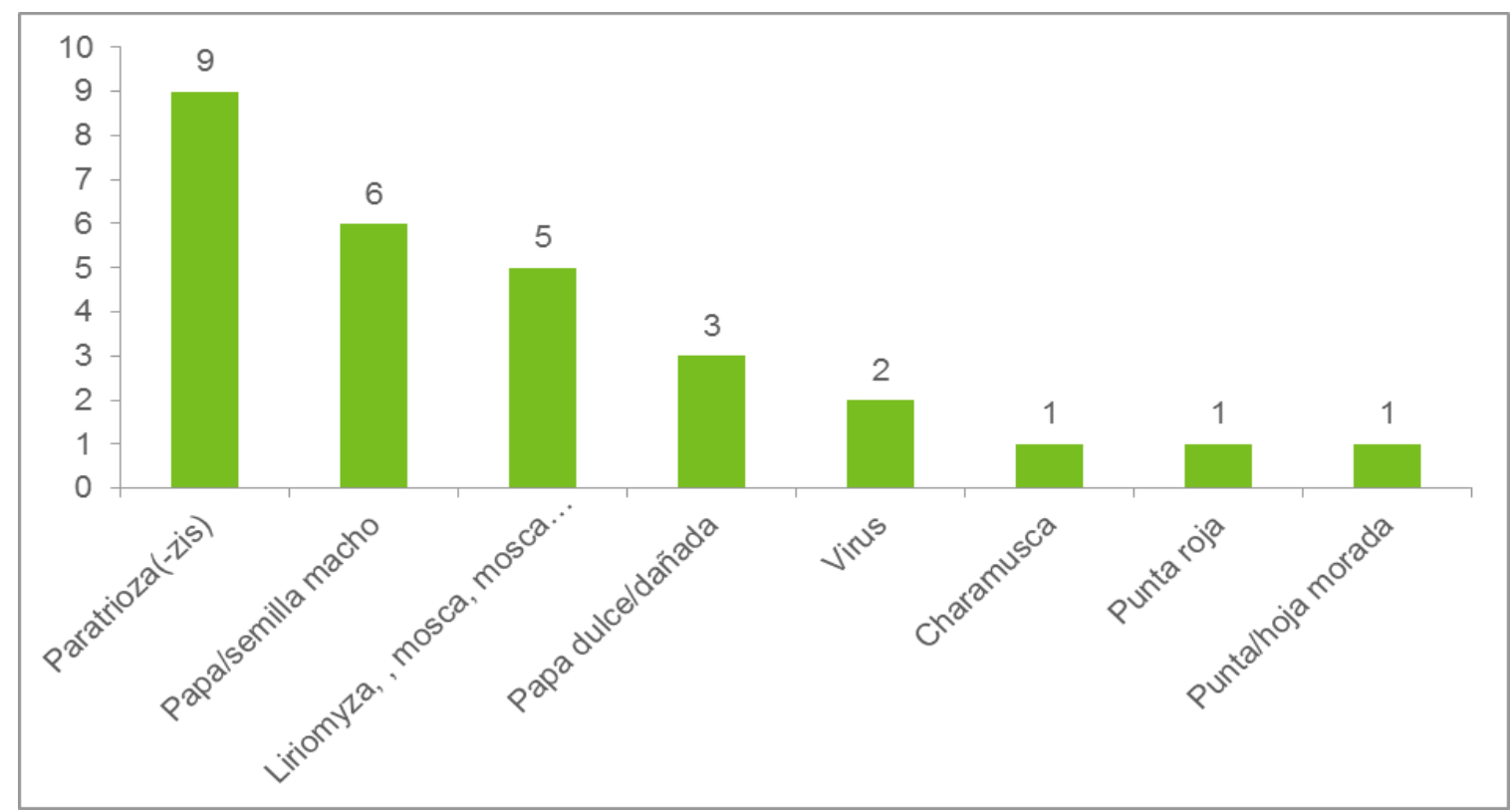

Figura 1. Nombres de la enfermedad usados por los agricultores entrevistados y la frecuencia de mención

La Figura 2 muestra que hay una tendencia hacia mayor conocimiento de los distintos síntomas entre los que habían participado en una jornada. Ocho de los 11 participantes de jornada reconocieren todos los cinco síntomas mostrados en las fotopáginas comparado con sólo dos de los noparticipantes.

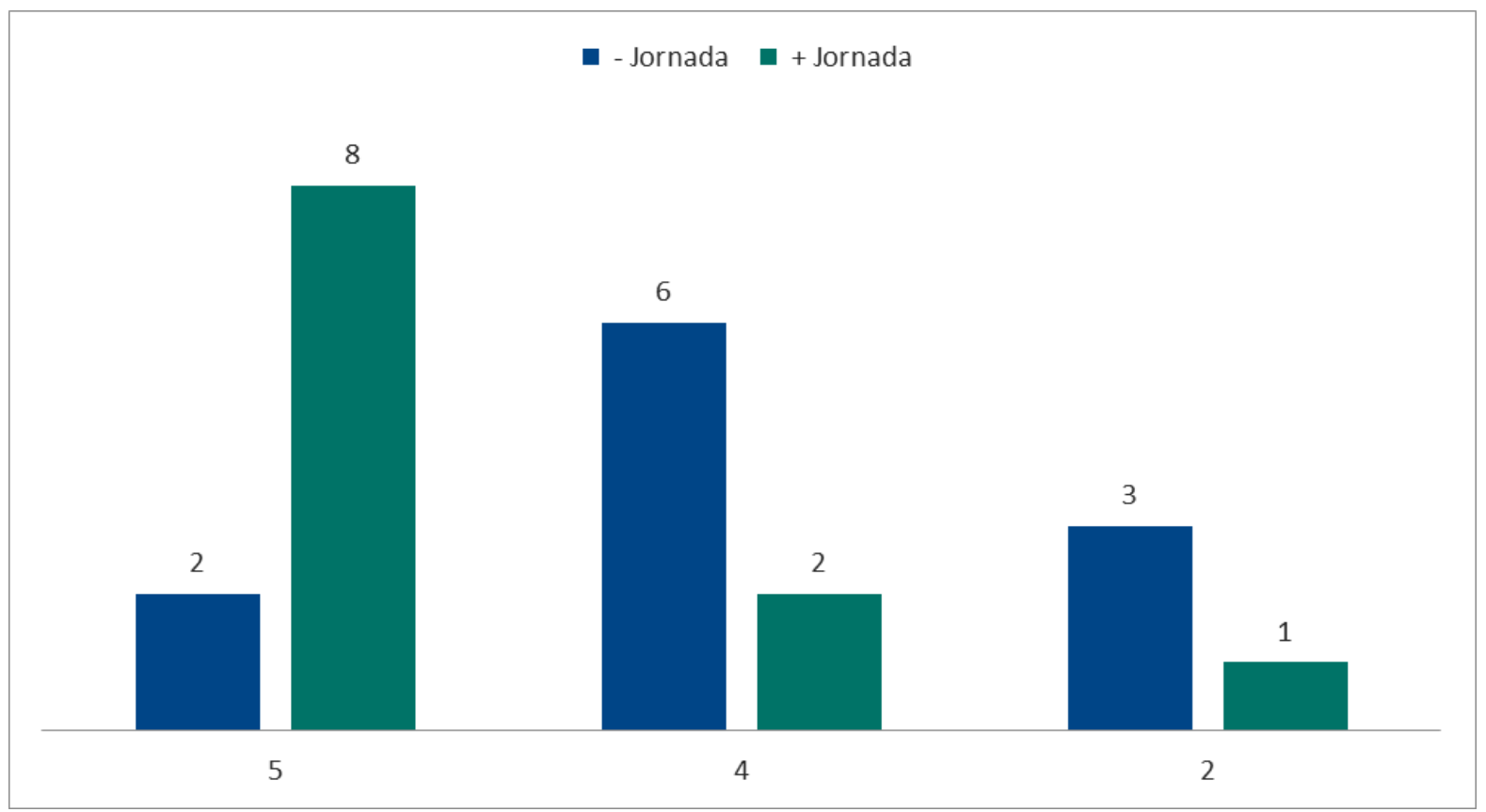

Figura 2. Número de síntomas identificados (x-axis) por los agricultores entrevistados (no. arriba de las columnas).

La misma tendencia se ve acerca del conocimiento de malezas hospederas (Figura 3). Una mayor proporción de los participantes de jornadas conocían todas las malezas hospederas comparado con los no-participantes. Sin embargo, no todos ellos conocían la relación entre las malezas y la 
diseminación de la plaga. Una señora, al darse cuenta que la mosca se multiplica en malezas como hierbamora y friegaplato dijo, "Ah, allí está el detalle. Ahora voy a arrancar la hierbamora."

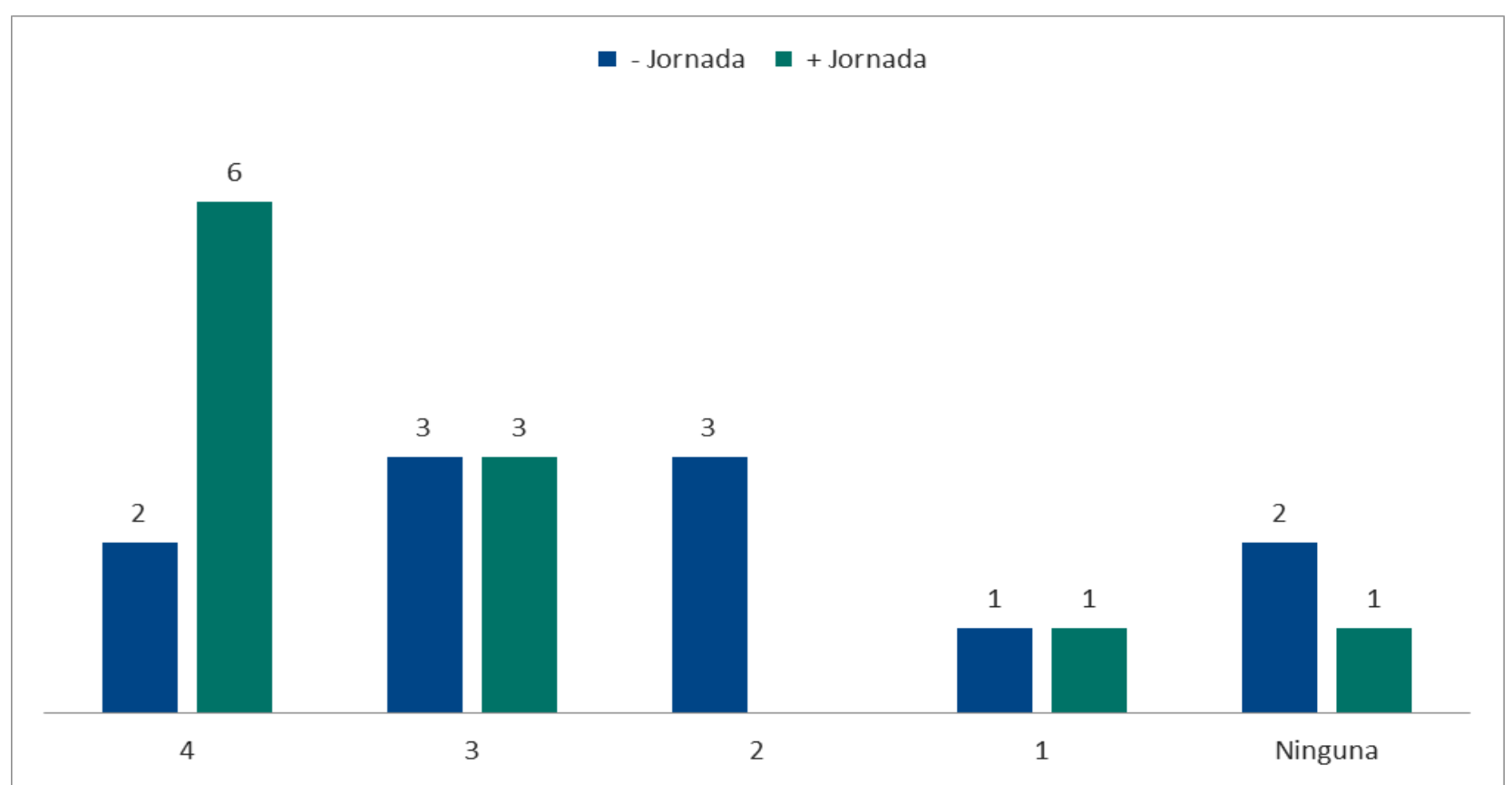

Figura 3. Número de malezas hospederas de paratrioza identificadas (x-axis) por los agricultores participantes (+jornada) y no-participantes (-jornada) en jornadas de salud de plantas (no. arriba de las columnas).

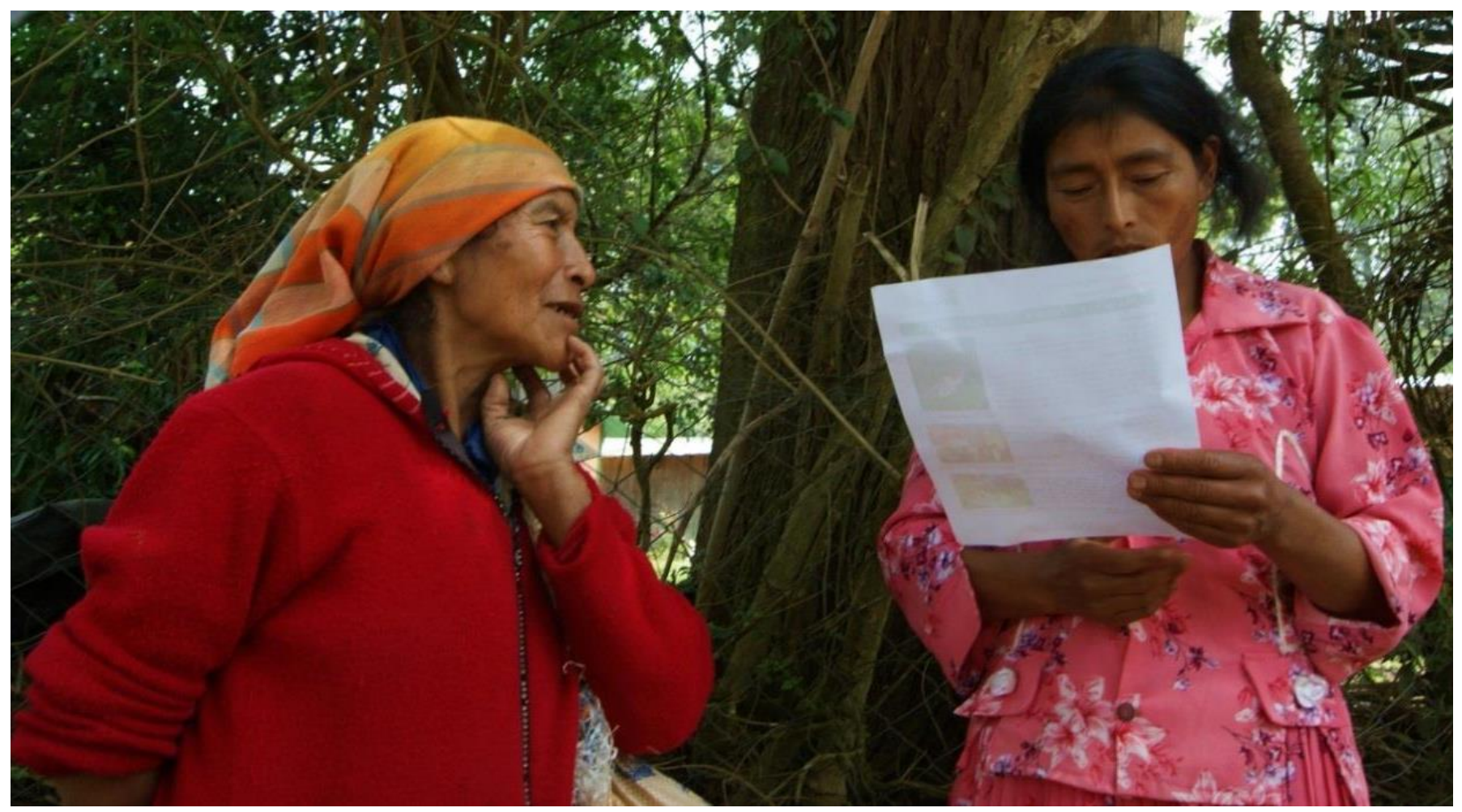

La señora Julia García (derecha) quería saber si es la misma especie de mosca que ataca a la papa y al tomate 


\section{Conocimiento y uso de las prácticas de control recomendadas}

Los once agricultores participantes de jornada indicaron que usan la información recibida (hoja volante) para tomar decisiones acerca del control de la paratrioza. Sin embargo, solo cuatro dijeron que aún conservan la hoja volante.

Entre las doce recomendaciones dadas para el manejo de la paratrioza, notamos una pequeña diferencia en conocimiento entre participantes y no-participantes de cuatro de ellas: usar trampa amarilla - evitar etiqueta roja - rotar productos - revisar parcelas para eliminar plantas con síntomas (ver Cuadro 2, resaltado en verde).

En cuanto al uso de las recomendaciones, tres fueron más frecuentes en el grupo de agricultores participantes de la jornada: eliminar malezas hospedantes - evitar etiqueta roja - rotar productos.

Otras prácticas son ampliamente conocidas y usadas por todos los agricultores: usar semilla certificada - pre-germinar semilla - descartar papa enferma. Estas son buenas prácticas agrícolas generales para la producción de papa. Por el contrario, nadie conocía la práctica de monitoreo (usar umbrales para determinar momento de aplicación).

La mayoría, tanto participantes como no-participantes, conocen el uso de barreras vivas.

Curiosamente, esta práctica es más usada por agricultores que no participaron en una jornada (ver Cuadro 2, resaltado en amarillo).

A continuación damos más detalles sobre algunas de las prácticas recomendadas. Los números se refieren a la lista de prácticas presentada en el Cuadro 2.

Cuadro 2 Conocimiento y uso de las recomendaciones incluidas en la hoja volante de parte de agricultores participantes (+jornada) y no-participantes (-jornada) en jornadas de salud de plantas

\begin{tabular}{|l|c|c|c|c|}
\hline \multirow{2}{*}{ Recomendación } & conoce la práctica & \multicolumn{2}{|c|}{ Usa la práctica $^{2}$} \\
\cline { 2 - 5 } 1 Limpiar terreno & +jornada & -jornada & +jornada & -jornada \\
\hline 2 Usar trampa amarilla & 8 & 9 & 7 & 0 \\
\hline 3 Eliminar hospedantes (malezas, papa voluntaria) & 10 & 5 & 0 & 6 \\
\hline 4 Usar barreras vivas & 10 & 9 & 2 & 5 \\
\hline 5 Usar semilla certificada & 9 & 9 & 10 & 8 \\
\hline 6 Pre-germinar semilla & 11 & 11 & 9 & 8 \\
\hline 7 Descartar/ enterrar papa enferma & 10 & 10 & 11 \\
\hline 8 Usar umbrales para determinar momento de aplicación & 0 & 0 & 0 & 0 \\
\hline 9 Evitar etiqueta roja & 11 & 7 & 9 & 4 \\
\hline 10 Rotar productos según ingrediente activo & 11 & 7 & 10 & 7 \\
\hline 11 Fumigar al envés de la hoja & 10 & 9 & 9 & 8 \\
\hline 12 Revisar la parcela y eliminar plantas con síntomas & 11 & 8 & 9 & 8 \\
\hline
\end{tabular}

(1) Los números incluyen respuestas 'un poco'

(2) Los números incluyen respuestas 'a veces'

P2 Usar trampas amarillas. Diez participantes de la jornada respondieron que sí conoce la práctica comparado con solo cinco de los no-participantes. Esto indica que la jornada ha tenido un efecto sobre el conocimiento de los agricultores. Sin embargo, nadie aún ha usado las trampas. Una persona dijo, "he escuchado de las trampas, pero no sé cómo usarla". Uno de los cinco no- 
participantes que conocen la práctica, indicó que no la usa debido al tiempo que toma armarlas y por el costo asociado.

P3 Eliminar hospedantes. Aunque casi todos los agricultores respondieron que si conocen la práctica de eliminar plantas hospederas (malezas o plantas voluntarias), sólo dentro del grupo de participantes de jornada hubo un alto grado de aplicación. Algunos indicaron que después de haber recibido la recomendación, empezaron a eliminar las plantas hospederas. Sin embargo los que no participaron en la jornada indicaron que chapean o limpian todo alrededor de su terreno como una actividad general, y parece que no asocian esta labor con la paratrioza.

P9 Evitar etiqueta roja. Todos los agricultores que asistieron a la jornada de salud saben que hay que evitar productos de etiqueta roja. De ellos nueve mencionaron que siguen esta recomendación porque saben que son agroquímicos "muy peligrosos" y los tratan de evitar. Aunque esta práctica no sirve directamente para controlar la paratrioza, es una política de seguridad de Plantwise que respeta los tratados internacionales que prohíben o restringen el uso de ciertos pesticidas ${ }^{4}$. Siete de los noparticipantes indicaron que sí saben que estos productos son peligrosos para la salud humana. El conocimiento de los agricultores sobre las etiquetas varía mucho. Dos dijeron no conocer las diferentes etiquetas [coloración] o no toman en consideración el color de las etiquetas.

P10 Rotar productos según ingrediente activo. Todos los agricultores que participaron en la jornada contestaron conocer la práctica de rotación de productos químicos. Sólo uno no la aplica. De los once no-participantes, siete sí conocen y aplican ésta práctica. Los participantes que sí usan la práctica dieron varias razones para hacerlo: 3 agricultores indicaron que rotan según el nombre en la etiqueta, 1 agricultor había recibido un programa de aplicaciones ofrecido por Ecaray ${ }^{5}$, y 2 agricultores sabían del riesgo de desarrollar resistencia ya que "todas las medicinas juntas a veces no funcionan". Los no-participantes que sí usan la rotación de productos, indicaron que alternan porque "el insecto se acostumbra al veneno". Particularmente llama la atención un agricultor que no participó en la jornada y que conoce de la práctica pero no la aplica porque dice que "aplico el mismo producto hasta que veo que ya no está funcionando". Luego cambia.

P12 Revisar la parcela y eliminar plantas con síntomas. 19 agricultores (11 participantes y 8 noparticipantes) indicaron conocer esta práctica. Ocho de cada grupo la aplican pero con distinta frecuencia. Los participantes de jornada dijeron que lo hacen una vez al día, casi todos los días o cada cuatro días. Entre los no-participantes la frecuencia es de tres a cuatro días o una vez por semana. Un agricultor de Azacualpa había entendido la importancia de esta práctica. "Cuando arranco una planta enferma la entierro. No la puedo dejar allí botada porque puede afectar a los vecinos", dijo.

\section{Control químico - el método preferido}

La aplicación calendarizada de 'medicina', como le llamaron algunos agricultores a los pesticidas, parece estar muy arraigada y difícil de cambiar, considerada por el joven Santos Neemías como una práctica 'común'. Aunque las jornadas trataron de introducir prácticas de uso racional de pesticidas a través de monitoreo del insecto, todos los entrevistados fumigan la papa con intervalos de dos veces por semana o cada tres a cuatro días. Aparentemente es difícil competir con los paquetes tecnológicos promovidos por otros oferentes. El hecho que nadie sabía de umbrales de acción muestra que no es fácil introducir nuevo conocimiento orientado a cambiar las costumbres de fumigación. Sin embargo un agricultor dijo buscar por plantas enfermas para poder determinar si se debe o no fumigar.

Según un oficial de SENASA los problemas son múltiples. "A veces usan cocteles y una dosis muy alta para el control de la paratrioza, y a veces hay problemas con la disponibilidad de productos," dijo. "Hay resistencia a los insecticidas por sobre uso. El problema es que cuando está alto el precio se les olvida rotar productos. Y son los mismos que usan en tomate, papa, berenjena etc. Así se perpetúa la

${ }_{5}^{4} \frac{\mathrm{https}: / / \text { www.plantwise.org/Uploads/Plantwise/Plantwise\%20Pesticide\%20Red\%20List.pdf }}{\text { Empresa secadora de papa en Intibucá }}$

Jornadas de salud para plantas en Intibucá, Honduras: El efecto sobre el conocimiento y las prácticas de control de paratrioza en papa 
presión de selección por individuos resistentes." Los doctores de plantas añadieron que hay problemas de eficiencia debido a métodos de aplicación inadecuados (ej. selección de boquilla).

La encuesta demuestra que los agricultores usan muchos productos diferentes. Los entrevistados reportaron un total de 22 productos utilizados para el control de la paratrioza (Cuadro 3). Doce de estos productos estaban incluidos dentro de los recomendados en la mini hoja volante (resaltados en verde) mientras siete no formaban parte de las recomendaciones hechas (celdas blancas). Tres de los productos reportados no eran insecticidas (celdas rosadas). Ninguno de los productos era de la clase toxicológica 1a o 1b (etiqueta roja). Como antes mencionado muchos dijeron que rotan pesticidas y evitan etiqueta roja (Cuadro 2). Esto parece confirmarse con la lista de productos reportados.

Cuadro 3. Productos usados por agricultores participantes (+jornada) y no-participantes (-jornada) de jornadas de salud de plantas (\# veces mencionado).

\begin{tabular}{|c|c|c|c|c|c|}
\hline $\begin{array}{l}\text { Formulación } \\
\text { (ingrediente activo }{ }^{1} \text { ) }\end{array}$ & Ejemplos & Clase $^{2}$ & $\begin{array}{c}\text { \# veces } \\
\text { mencionado }\end{array}$ & $\begin{array}{c}+ \\
\text { jornada }\end{array}$ & $\stackrel{-}{-}$ \\
\hline Abamectina & Newmectin, Abamectin & Clase II & 1 & 1 & 0 \\
\hline Clorpirifos & Lorsban & Clase III & 5 & 2 & 3 \\
\hline Extracto de ajo & Bralic & Clase IV & 2 & 1 & 1 \\
\hline Extracto de chile y ajo & Chile/ajo con guaro & Clase IV & 1 & 0 & 1 \\
\hline Imidacloprid & Confidor & Clase III & 1 & 0 & 1 \\
\hline Imidacloprid+deltametrina & Muralla & Clase II & 1 & 1 & 0 \\
\hline Spirotetramat & Movento & Clase III & 2 & 2 & 0 \\
\hline Thiacloprid+beta-cyfluthrina & Monarca & Clase II & 1 & 1 & 0 \\
\hline Thiamethoxam & Actara & Clase IV & 5 & 2 & 3 \\
\hline Tiametoxam+Lambdacialotrina & Engeo & Clase II & 3 & 2 & 1 \\
\hline \multicolumn{3}{|c|}{ Sub-total productos recomendados durante la jornada de salud } & 22 & 12 & 10 \\
\hline Extracto de planta suculenta & Chancho de monte & Clase IV & 1 & 1 & 0 \\
\hline Flupyradifurone & Sivanto & Clase III & 1 & 1 & 0 \\
\hline Hidrogenooxalato de tiociclam & Evisect & Clase III & 2 & 1 & 1 \\
\hline Profenofós + Lufenurón & Curyom & Clase II & 13 & 3 & 10 \\
\hline Lambdacialotrina & Karate & Clase II & 2 & 1 & 1 \\
\hline Diazinon & Diazinon & Clase II & 3 & 1 & 2 \\
\hline Bifentrina & Kung Fu & Clase II & 1 & 0 & 1 \\
\hline \multicolumn{3}{|c|}{ Sub-total productos no recomendados durante la jornada de salud } & 23 & 8 & 15 \\
\hline Mancozeb + cimoxalino & Moxan & - & 1 & 0 & 1 \\
\hline Mancozeb & Ditano & - & 1 & 0 & 1 \\
\hline Diclosulam & Conex & - & 1 & 1 & 0 \\
\hline \multicolumn{3}{|c|}{ Sub-total productos incorrectos para el control de la paratrioza } & 3 & 1 & 2 \\
\hline Total & & & 48 & 21 & 27 \\
\hline
\end{tabular}

(1) Productos resaltados en verde son recomendados en las jornadas. Los resaltados en rosado son fungicidas o herbicidas

(2) Clase I: mayor toxicidad; Clase IV: menor toxicidad (según la Organización Mundial de la Salud) 
La encuesta indica que los no-participantes tienden a usar predominantemente productos clase II (banda amarilla) mientras que los que participaron en las jornadas han aumentado el uso de productos clase III y IV que son de menor toxicidad (Figura 4). La diferencia más marcada entre participantes y no-participantes se nota en el uso de Curyom (celdas amarillas), un producto clase II que no está dentro de los productos recomendados por SENASA para el manejo de paratrioza.

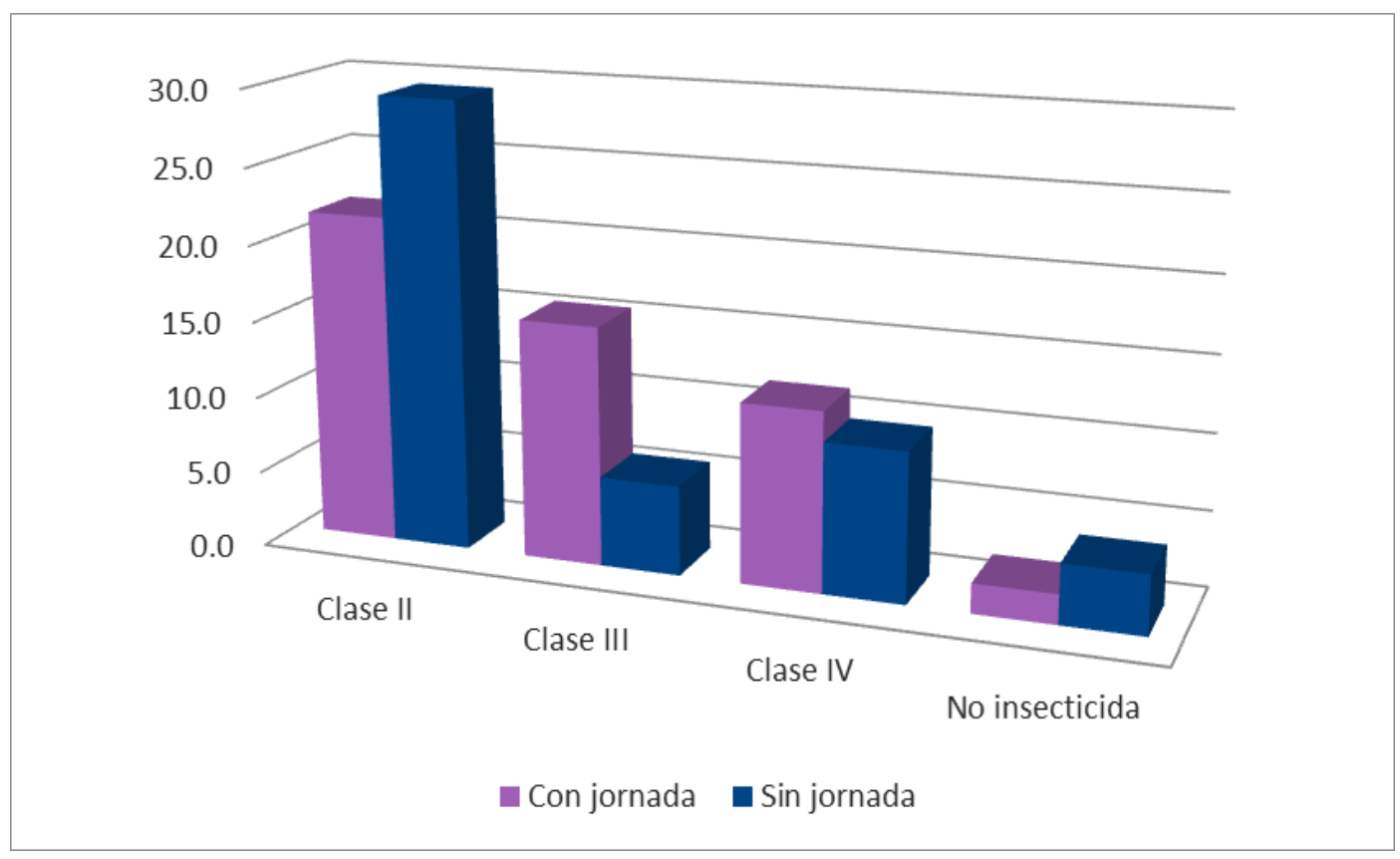

Figura 4. Porcentaje de reportes de uso de plaguicidas por agricultores con y sin participación en las jornadas

La frecuencia de mención de productos recomendados durante las jornadas muestra una proporción alta de productos $(70 \%)$ de baja toxicidad lo cual indicaría un riesgo bajo del desarrollo de resistencia e impacto a la salud humana (Figura 5A). Sin embargo la tendencia mayor, sobre todo en agricultores no-participantes de jornadas, es utilizar productos banda amarilla no recomendados (clasificación toxicológica II) (Figura 5B y Cuadro 3).

Clase II $\square$ Clase III $\square$ Clase IV $\square$ No insecticida

A

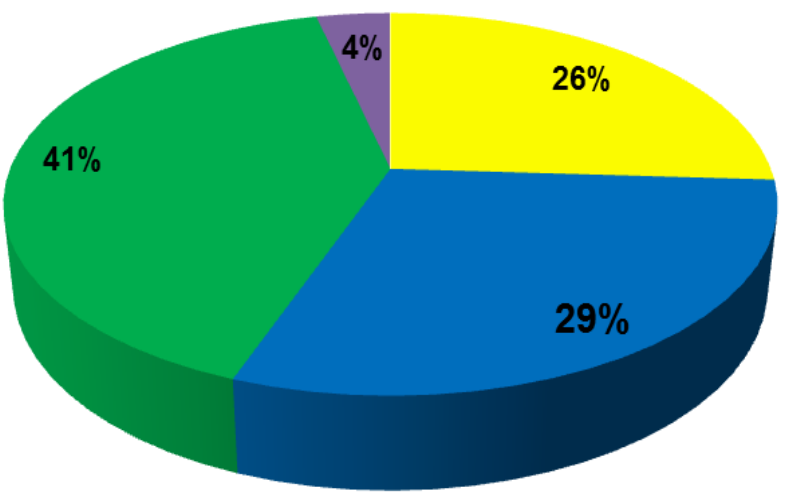

Clase II $\because$ Clase III $\because$ Clase IV $\because$ No insecticida

B

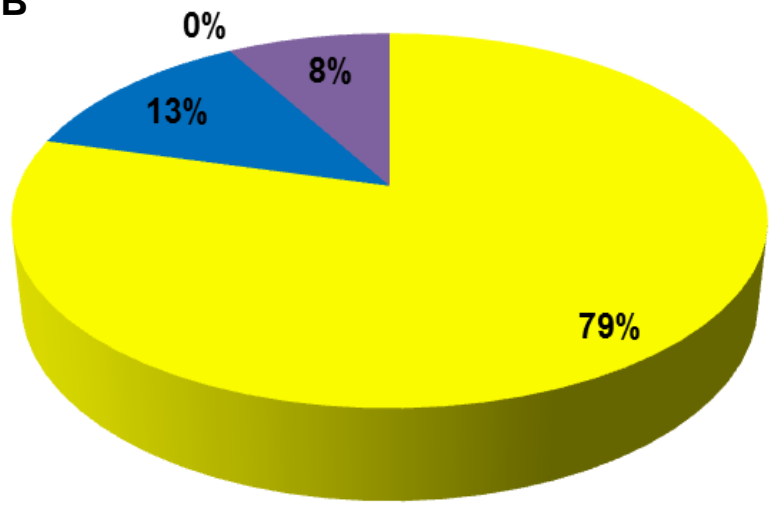

Figura 5 Frecuencia de mención de plaguicidas recomendados durante las jornadas $(A)(n=24)$ vs. NO recomendados durante las jornadas $(B)(n=23)$ para el control de paratrioza de acuerdo a su toxicidad. 


\section{Impacto de la paratrioza sobre la producción de papa en Intibucá}

Los bajos precios en el mercado y la alta presión de la paratrioza hacen que sea poco rentable sembrar papa. No hay incentivos para invertir en el control de la plaga y eso puede empeorar el problema. Oímos de casos de agricultores que abandonan la papa en la parcela porque es muy costoso tratarla. Así se propaga rápidamente la plaga. Una agricultora entrevistada dijo: "Es una enfermedad que ha llegado a hacer más pobre a los campesinos. No se puede controlar. Uno se desmotiva con los bajos precios."

Una agricultura de Río Grande confirmó que ya no es atractivo sembrar papa. "No estamos sembrando papa este año," dijo. "Requiere de mucha inversión por ejemplo para riego y control de la paratrioza. Nosotros no podemos. Somos de escasos recursos."

Una ordenanza municipal fue desarrollada en Intibucá para obligar a los agricultores de papa a desechar apropiadamente los residuos de cosecha (tubérculos y plantas) para reducir la plaga, sin embargo, los cambios políticos han retrasado la implementación de esta ley.

La situación se está poniendo urgente. En los últimos años, la paratrioza y la bacteria han comenzado a causar daños en otros países en la región y se han reportado en otros cultivos. En Guatemala y México existen reportes en papa, mientras que los hay en tabaco en Honduras y Nicaragua, tomate en El Salvador y berenjena en Honduras (Bextine et al. 2013a; Bextine et al. 2013b; Munyaneza et al. 2009; Munyaneza et al. 2013a; Munyaneza et al. 2013b; Palmieri et al. 2012). Es por esto que se deben aunar esfuerzos, tanto en Honduras como en la región centroamericana, para que el agricultor pueda controlar la plaga y así evitar propagar la enfermedad y causar aún mayores pérdidas.

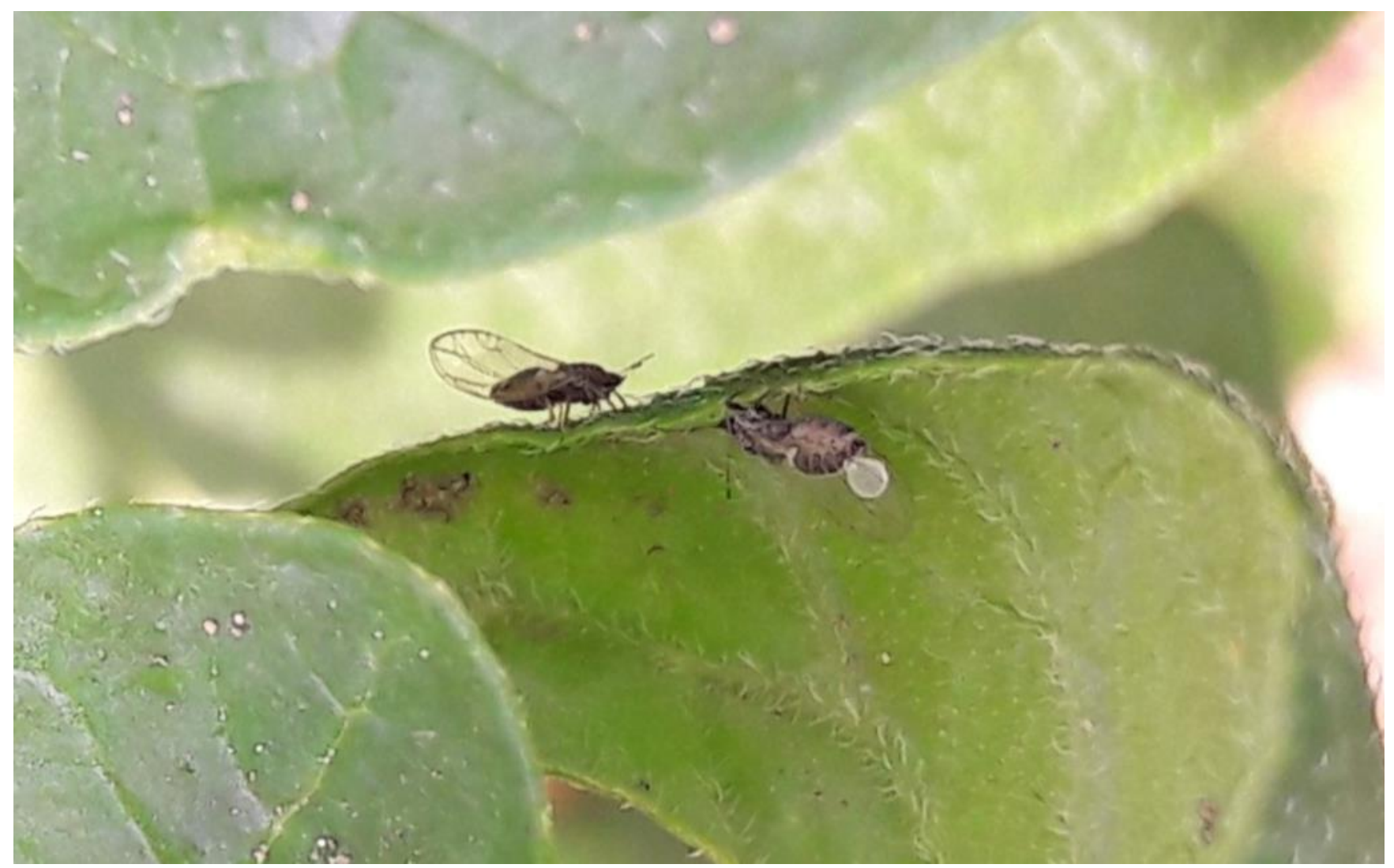

La mosca (psílido) paratrioza depositando su huevo bajo una hoja de papa 


\section{El éxito de la Doña Esperanza Meza}

Doña Esperanza ha logrado mantener un cultivo sano a pesar de la alta presión de la plaga. Ella ha seguido las recomendaciones de manejo brindadas por un proyecto de USAID y los doctores de plantas de SENASA durante las jornadas de salud. Esperanza usa semilla certificada de la variedad Arnova que es menos susceptible a paratrioza. También realiza monitoreo para la detección temprana de la plaga y eliminación de papa voluntaria. Aplica insecticidas como Karate, Actara, Newmectin, Engeo y Abamectin. Esto le ha permitido tener buena cosecha y aunque los precios de la papa están bajos, ella puede vender su producto como semilla alcanzando mayores ganancias.

Anteriormente, doña Esperanza no controlaba las plantas voluntarias, en sus propias palabras, "antes no lo hacía, ya que no le daba importancia". Simplemente tenía un calendario de aplicación de plaguicidas que rondaba los 8 y 15 días para prevenir la plaga. Ahora tiene una finca próspera y bien manejada. Tiene dos plantaciones en El Rodeo, una de 9 tareas ${ }^{7}$ sembrada con papa Arnova y otra de 4 tareas sembrada con Bellini. Debido a su buen manejo es reconocida por la comunidad y profesionales que le visitan.

Doña Esperanza ha mejorado su producción tanto que de cada compra de semilla certificada puede realizar dos siembras usando semilla seleccionada de su propia cosecha.

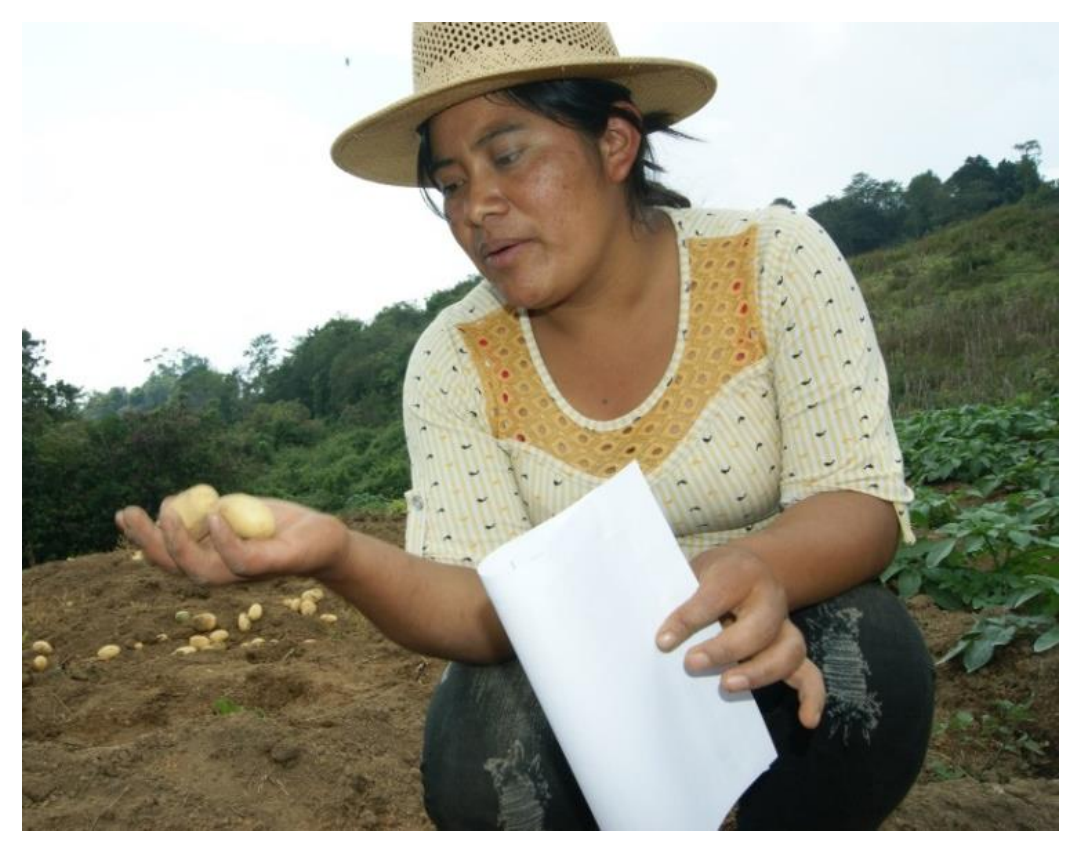

Doña Esperanza recibe un mejor precio por su papa al venderla como semilla a sus vecinos, sin importar que en el mercado el precio esté malo. Ella logra vender a 1,000 lempiras ${ }^{6}$ por quintal, mientras que si le vende al "coyote", recibiría solo 500 lempiras. Ella saca de 8 a 10 quintales $^{8}$ por tarea, alcanzando el promedio nacional de producción de 10 quintales por tarea (Toledo, 2013).

Algunas de las prácticas recomendadas no las cumple en su totalidad, porque a veces es difícil conseguir los materiales o el tiempo no le permite. Por ejemplo, el pegamento necesario para la elaboración de las trampas amarillas no se consigue. "No conozco vecinos que lo hagan," dice. En otras ocasiones, por tiempo no desmaleza lo suficiente.

\section{Las jornadas como mecanismo de diseminación de información}

El uso de hojas volantes tiene ventajas porque el agricultor puede llevarse a casa la información para procesarla y usarla más tarde en su cultivo. También puede compartirla con su familia y los vecinos. Sin embargo, para ser un método efectivo para diseminar información técnica, las hojas volantes tienen que ser claras y fáciles de entender. En la hoja volante usada para las jornadas sobre paratrioza hay 12 opciones de manejo; de las cuales no se comunica claramente las acciones más importantes para lograr un control efectivo. También podría haber más detalles sobre el modo de aplicación.

El nivel de educación varía entre los agricultores. No todos saben leer o no tienen la costumbre de leer. El hecho que sólo cuatro de los participantes de las jornadas habían guardado la hoja entregada

\footnotetext{
61 USD = 23 lempira (HNL)

71 tarea $=0.062$ hectáreas o $620 \mathrm{~m}^{2}$

81 quintal = 100 libras o $46 \mathrm{~kg}$
}

Jornadas de salud para plantas en Intibucá, Honduras: El efecto sobre el conocimiento y las prácticas de control de paratrioza en papa 
muestra que el material escrito no siempre tiene la duración esperada. Otro limitante es que las personas mayores muchas veces no pueden leer la hoja porque no tienen anteojos.

Hay mucha necesidad de mejorar los servicios para los agricultores en un país donde la cobertura de la asistencia técnica es muy baja (4.2\% según INE, 2008). SENASA y otras instituciones públicas tienen poca capacidad y recursos. A pesar de la baja cobertura de asistencias técnica en Honduras, ha sido un desafío atraer a muchos agricultores a las jornadas. Esto puede ser motivado por lo dispersos que están los productores en la región, las largas distancias que tienen que recorrer para acudir a los eventos y la escasez de transporte.

En esta región un alto porcentaje de la población es de la etnia Lenca, uno de los grupos socioeconómicos menos favorecidos del país. Múltiples organizaciones los visitan periódicamente dentro del marco de proyectos de asistencia en varias áreas. Esto puede afectar la disponibilidad o disposición de los productores para trasladarse para participar en las jornadas de salud de plantas.

Por el momento las intervenciones tienden a ser fragmentadas y descoordinadas. Puede crear confusión entre los agricultores si reciben diferentes

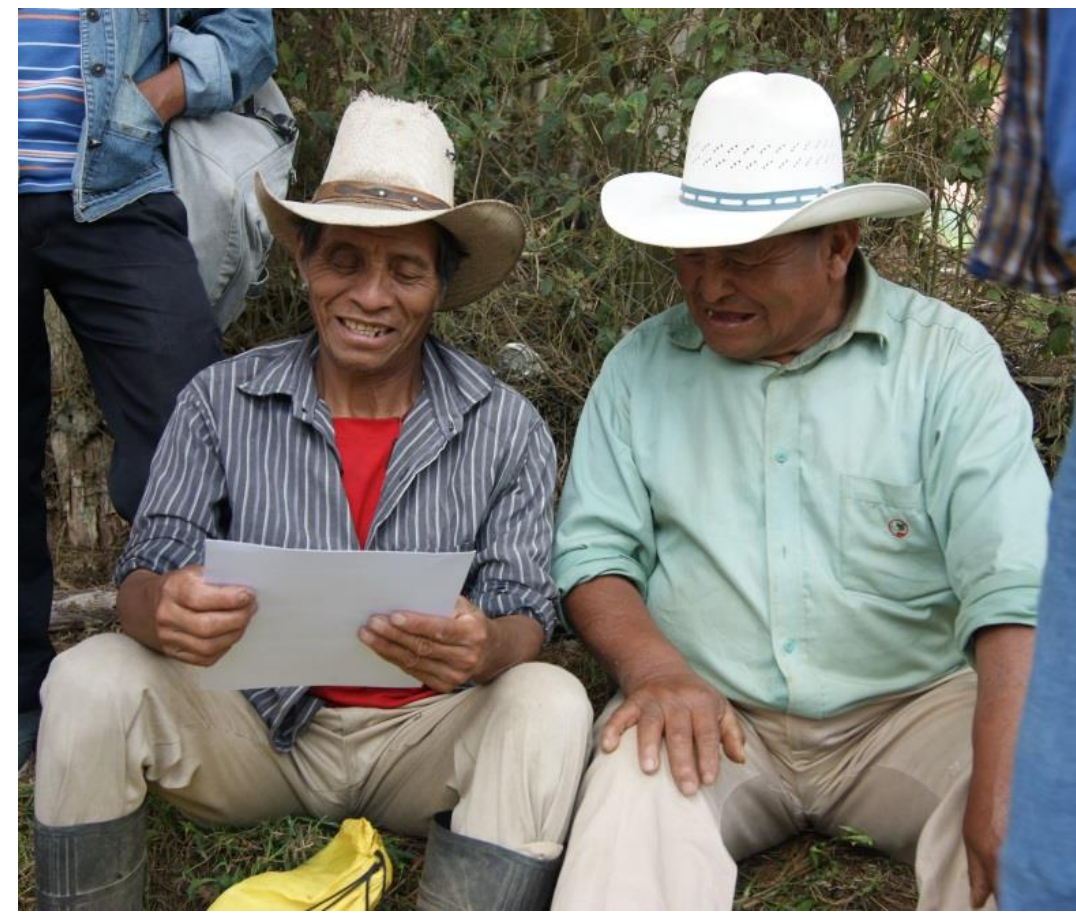

Dos agricultores entrevistados tratan de leer la hoja volante. EI señor a la derecha tuvo que sacar anteojos prestados para poder leerla. recomendaciones de diferentes servicios. Algunas de las personas entrevistadas mencionaron que han recibido materiales y charlas de otras organizaciones, y por lo visto, tienen problemas en distinguir quien les visitó. Pero la impresión en muchos de los casos es que el agricultor sí recuerda que tienen que aplicar insecticida cada 4 días. La mayoría de los oferentes que visitan la zona con ayuda técnica para los agricultores enfocan sus recomendaciones en el monitoreo, eliminación de residuos de cultivo y aplicación de insecticidas. Los mensajes tienen que ser mejor alineados.

Es necesario fortalecer las alianzas con otros oferentes de servicios (proyectos, cooperativas y ONG) que tienen contacto más continuo con los agricultores para así crear sinergia y aprovechar al máximo los recursos limitados.

\section{Recomendaciones para mejorar}

- Mejorar la comunicación y colaboración con otros oferentes de asistencia técnica en la zona (USAID, Ecaray etc.) para uniformizar las recomendaciones y alcanzar a más gente con mensajes de calidad

- Mejorar la articulación con las municipalidades, para incrementar la participación de los productores

- Explorar opciones para crear sinergia, por ejemplo, combinando métodos y aprovechando nuevas tecnologías, como WhatsApp, para fortalecer la acción colectiva

- Revisar la hoja volante enfocando en lo más esencial para evitar que el mensaje se diluya y confunda 
- El uso de bioplaguicidas debería promocionarse más. Hay un par de compañías que podrían dar apoyo y realizar pruebas de eficacia de algunos bioplaguicidas en fincas locales. Este tipo de actividad se podría combinar con demostraciones de campo y jornadas de salud para aumentar su alcance

\section{Conclusiones}

La paratrioza es una plaga desafiante por su ciclo de vida y los daños directos e indirectos que causa. Requiere mucho conocimiento de la plaga y el cultivo para obtener un control efectivo.

El estudio de caso muestra que las jornadas pueden contribuir a aumentar el conocimiento de los agricultores sobre la plaga, llevándose a la adopción de algunas prácticas mejoradas como la eliminación de malezas hospedantes, rotación de productos y la evasión de productos de etiqueta roja. Sin embargo, la aplicación calendarizada de insecticidas sigue siendo una práctica muy arraigada y difícil de cambiar. Un efecto positivo de las jornadas parece ser el aumento en uso de químicos menos tóxicos.

Para aumentar la eficiencia y eficacia de las jornadas y otras acciones de extensión es necesario mejorar los mensajes entregados a los agricultores y fortalecer la coordinación con otros oferentes. La acción colectiva es indispensable para el control efectivo de la paratrioza y la reducción del uso de insecticidas. No es suficiente con que unos pocos apliquen buenas prácticas si la mayoría no lo hacen, especialmente si las parcelas se encuentran relativamente cerca o contiguas.

Los agricultores y oferentes de servicios enfrentan múltiples desafíos para controlar esta plaga tan devastadora. El actual bajo precio de la papa agrava la situación ya que muchos agricultores de escasos recursos no pueden invertir lo suficiente en el control de la enfermedad, empeorando así el problema. Es un desafío

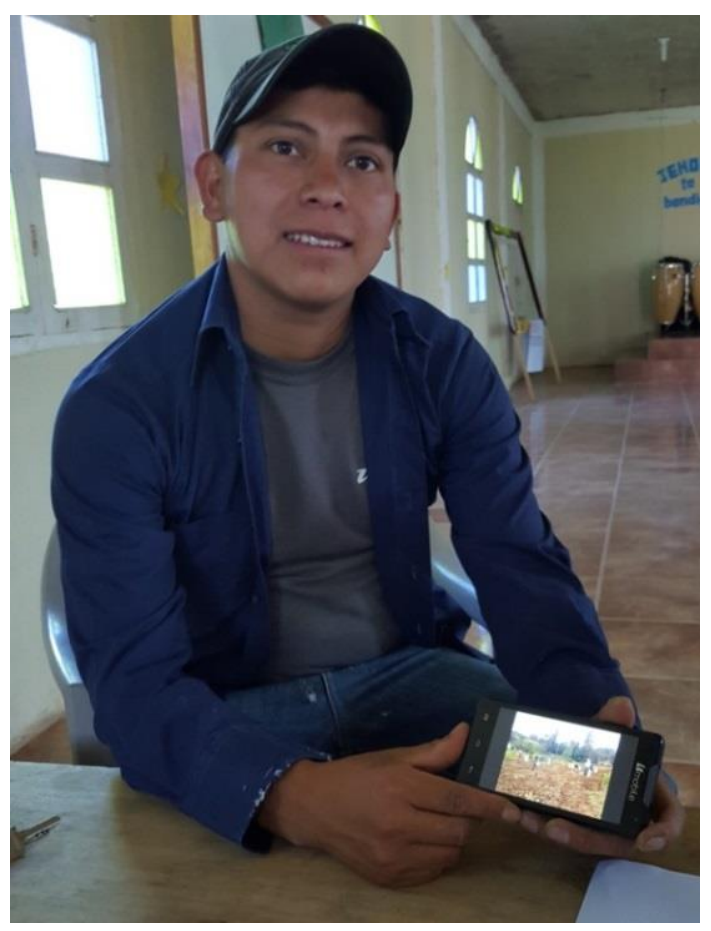

Jaime Vásquez Pineda muestra una foto que tomó en su parcela con su celular. Es posible que los jóvenes, en muchos casos usuarios de celulares de última generación, se conviertan en un enlace entre las comunidades de agricultores $y$ los proveedores de servicios técnicos mediante WhatsApp. nacional fuera del alcance de agricultores individuales. Por lo tanto el compromiso y el apoyo del gobierno local y central son imprescindibles. 


\section{Referencias}

Bextine, B.; Arp, A.; Flores, E.; Aguilar, E; Lastrea, L.; Soza Gomez, F; Powell, C. y Rueda, A. 2013a. First Report of Zebra Chip and 'Candidatus Liberibacter solanacearum' on Potatoes in Nicaragua. Plant Disease 97:1109. Estados Unidos.

Bextine, B.; Arp, Aguilar, E; Rueda, A.; Caceres, O.; Sengoda, V.G; McCue, K.F. y Munyaneza, J.E. 2013b. First Report of "Candidatus Liberibacter solanacearum" on Tomato in El Salvador. Plant Disease 97:1245. Estados Unidos.

Bujanos M., R; Ramos M., César. 2015. El psílido de la papa y tomate Bactericera (=paratrioza) cockerelli (Sulc) (Hemiptera: Triozidae): ciclo biológico; la relación con las enfermedades de las plantas y la estrategia del manejo integrado de plagas en la región del OIRSA. Organismo Internacional Regional de Sanidad Agropecuaria. El Salvador.

DICTA. 2016. Manejo dela paratrioza (Bactericera cockerelli) en el cultivo de la papa. La Dirección de Ciencia y Tecnología Agropecuaria (DICTA), de la Secretaría de Agricultura y Ganadería (SAG). Honduras.

Espinoza, H.R. 2010. Facing the Bactericera Cockerelli-Candidatus Liberibacter Complex in Honduras. Proceedings of the 10th Annual Zebra Chip Reporting Session, 7-10 Noviembre 2010, Texas, Estados Unidos.

Espinoza, H.R.; Rivera, J.M.; Brown, J.K.; Weller, S. 2014. Manejo integrado de plagas de papa en Honduras. Fundación Hondureña de Investigación Agrícola (FHIA). Honduras.

FHIA. 2011. El Psílido de la Papa o Paratrioza Un enemigo que daña importantes cultivos en Honduras. Hoja Técnica No. 9. Fundación Hondureña de Investigación Agrícola (FHIA). Honduras.

Munyaneza, J.E.; Sengoda, V.G.; Crosslin, J.M.; Garzón-Tiznado, J.A. y Cardenas-Valenzuela, O.G. 2009. First Report of "Candidatus Liberibacter solanacearum" in Pepper Plants in México. Plant Disease 93:1076. Estados Unidos.

Munyaneza, J.E.; Sengoda, V.G.; Aguilar, E.; Bextine, B. y McCue, K.F. 2013a. First Report of "Candidatus Liberibacter solanacearum" Associated with Psyllid-Infested Tobacco in Nicaragua. Plant Disease 97:1244. Estados Unidos.

Munyaneza, J.E.; Sengoda, V.G.; Aguilar, E.; Bextine, B. y McCue, K.F. 2013b. First Report of 'Candidatus Liberibacter solanacearum' Infecting Eggplant in Honduras. Plant Disease 97:1654. Estados Unidos.

INE. 2008. Encuesta Agrícola Nacional 2007-2008. Tenencia, Uso de Tierra, Crédito y Asistencia Técnica. Instituto Nacional de Estadísticas (INE). Honduras.

OIRSA. 2016. Boletín Clima y Sanidad Agropecuaria No. 2. Organismo Internacional Regional de Sanidad Agropecuaria (OIRSA). El Salvador.

Palmieri, M.; Mejía, F.; Polanco, M.; Mansilla, F.; Donis, I.; Catalán, A.; López, W. y López A. 2012.

Caracterización de Patógenos, Vectores y Hospederos de la Papa Rayada en Guatemala. Informe final Consejo Nacional de Ciencia y Tecnología, Secretaría Nacional de Ciencia y Tecnología, Fondo Nacional de Ciencia y Tecnología y la Universidad del Valle de Guatemala. Guatemala.

Rehman, M., J. Melgar, C.J.M. Rivera, N. Urbina, A.M. Idris, y J.K. Brown. 2010. First report of "CandidatusLiberibacter psyllaurous" or "Ca. Liberibacter solanacearum" associated with severe foliar chlorosis, curling, and necrosis, and tuber discoloration of potato plants in Honduras. Plant Disease 94:376.

Toledo, M. 2013. El cultivo de la papa en Honduras. La Esperanza, Intibucá. Secretaría de Agricultura y Ganadería. Dirección de Ciencia y Tecnología Agropecuaria (DICTA). Honduras. 


\section{Reconocimientos}

\section{Donantes}

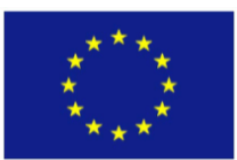

Irish Aid

Rialtas na hÉireann Government of Ireland

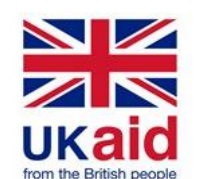

IFAD

INTERNATIONAL AGRICULTURAL
Ministry of Foreign Affairs of the Netherlands

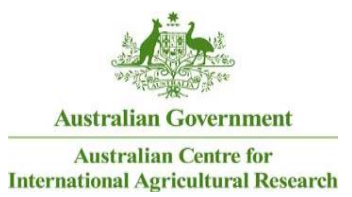

I. Schweizerische Eidgenossenschaft

Confédération suisse Confederazione Svizzer Swiss Agency for Development and Cooperation SDC

Ministry of Agriculture, People's Republic of China

\section{Colaboradores}

(db) CABI

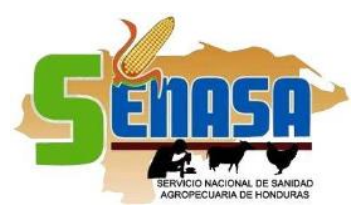

\section{Texto y fotos}

Eduardo Hidalgo, CABI Costa Rica

Hernán Arias, SENASA Comayagua

Henry Matute, SENASA Comayagua

Rony Vásquez, SENAZA Comayagua

José Gómez, CABI Brasil

Sol Danielsen, CABI Holanda

\section{Agradecimientos}

Agradecemos a las autoridades de la municipalidad de Intibucá, al señor Pedro Domínguez, líder comunal y funcionario de USAID y a la Cadena de la Papa por su colaboración en la convocatoria de productores durante el periodo de ejecución de las de jornadas, y a los productores y productoras que compartieron sus experiencias y percepciones durante las entrevistas hechas para el presente trabajo.

\section{Equipo de edición}

Sol Danielsen, José Gómez, Eduardo Hidalgo, Yelitza Colmenárez

\section{Cómo citar este documento}

Hidalgo, E., Arias, H., Matute, H., Vásquez, R., Gómez, J., Danielsen, S. 2017. Jornadas de salud para plantas en Intibucá, Honduras: el efecto sobre el conocimiento y las prácticas de control de paratrioza en papa. CABI Reseñas de Estudio 23.

DOI: https://dx.doi.org/10.1079/CABICOMM-62-8112 